\title{
Innovation by Collaboration between Startups and SMEs in Switzerland
}

\author{
Fabio Mercandetti, Christine Larbig, \\ Vincenzo Tuozzo, and Thomas Steiner
}

\author{
"We cannot solve our problems with the same") \\ thinking we used when we created them.
}

Albert Einstein (1879-1955)

Theoretical physicist and Nobel laureate (1921)

\begin{abstract}
Open innovation is key to the success of many companies. It is based on the intelligent use of all possible resources, including collaborations with parties outside the firm. Although it is well known that large companies foster and use startups as experiments in their innovation process, little is known about similar activities with small and mediumsized enterprises (SMEs). The aim of this article is to report the results of research done in Switzerland on startups and SMEs. It reveals that most startups know that they must co-operate with other companies from the very beginning of their existence, and that both sides have difficulties in performing a systematic search for possible partners. Hence, to encourage the collaborative development of innovative solutions, we propose building bridges between startups and SMEs, making the identification of possible users of new technologies (SMEs) more accessible to startups, as well as making startups more identifiable by SMEs.
\end{abstract}

\section{Introduction}

Even though Albert Einstein was best known for his work in physics, many of his principles and practice of teaching are transferable to business. When he said that, "we cannot solve our problems with the same thinking we used when we created them", he was basically describing the ability to solve problems by "thinking outside the box", which is a competence that sets many startups apart from larger companies. Indeed, startups are seen as a potentially rich source of novel ideas by other companies seeking to bring innovations to market.

In Switzerland, large companies such as Swisscom or SBB offer startups platforms for developing innovative ideas (e.g., the Pirate Hub in Zurich; tinyurl.com/y96acyu3). Such companies consider it an affordable approach to scan the business environment and then identify and consequently exploit innovative ideas outside their established businesses. Often, they systematically seek startups and support them not only financially, but also by providing them with infrastructure, advice, and know-how. At the same time, startups seek support from large companies because the potential boosting effect appears to be substantial.

However, this article has a more narrow focus on systematic, contractually defined collaborative innovation activity between startups and small and medium-sized enterprises (SMEs). SMEs form the vast majority of commercial enterprises in Switzerland, where $99.7 \%$ of companies have fewer than 250 full-time employees (Swiss Confederation, 2014). Although much of the focus is on collaboration between startups and large companies, due to their economic weight, SMEs could support and collaborate with considerably more startups than large companies do. SMEs could then enhance their own innovation process with limited investments.

Despite the economic significance of SMEs, we are only aware of relevant studies by Lichtenthaler (2011) and Vanhaverbeke and colleagues (van de Vrande et al., 2009; Vanhaverbeke et al., 2012), who researched the practice of open innovation in SMEs and their collaborations with startups. Likewise, in Switzerland, cases of 


\title{
Innovation by Collaboration between Startups and SMEs in Switzerland
}

\author{
Fabio Mercandetti, Christine Larbig, Vincenzo Tuozzo, and Thomas Steiner
}

best practices of SMEs that innovate thanks to collaborations with startups are scarce. Given that the number of newly founded companies per year in Switzerland is substantial when compared to the country's size and exceeded 42,000 in 2014 alone (Swiss Confederation, 2014), it cannot be said that the substrate for such partnerships is missing. There must be other reasons that explain the low number of open innovation initiatives between Swiss startups and SMEs.

This research addresses how collaborations between startups and SMEs can be encouraged, and it presents measures to foster such collaborations. We review the theory and literature of open innovation and place it at the level of startups and SMEs. In addition, we focus on collaboration and the literature addressing SMEs' involvement of startups in their innovation process. Our research was conducted in the context of an industry project (Steiner, 2015) and a bachelor thesis (Tuozzo, 2016) at the Lucerne University of Applied Sciences and Arts (HSLU) in Switzerland.

\section{Theoretical Background}

This section provides a background to the study by including definitions of terms and concepts related to open innovation and collaboration among companies, and by referencing literature about how large companies and SMEs approach startups.

\section{Open innovation and collaboration}

Open innovation allows the incorporation of solutions and innovation in the form of ideas, products, or technologies that could not be generated by the organization on its own. Chesbrough and Crowther (2006) state that "firms can and should use external ideas as well as internal ideas, and internal and external paths to market, as the firms look to advance their technology". The do-it-yourself approach in technology and research and development (R\&D) is inadequate to compete within today's business environment: finding partners and collaborations is essential for organizations (Pénin et al., 2011). Consequently, collaboration with partners along the value chain does not only offer new competitive options, it also forces a firm to define what type of knowledge it needs to source from external partners and what internal knowledge might be licensed out or sold (Vanhaverbeke \& Roijakkerspp, 2013).

The concept of open innovation comprises the exploitative and the explorative approaches to collaboration (Holmes \& Smart, 2009):
- The exploitative approach is "the use and development of things already known" (Levinthal \& March, 1993). That is, the approach involves a firm reinforcing its existing relationships to use and develop its current knowledge base. Given that firms can rely on prior experience and trust, the predictability, reliability, and efficiency of collaboration are enhanced (Lavie \& Rosenkopf, 2006). Associated terms are: refinement, choice, production, efficiency, selection, implementation, and execution (March, 1991).

Repetition-based improvement, experiential learning, and specialization are associated with exploitation (Lavie \& Rosenkopf, 2006).

- The explorative approach in forming collaborations with new partners involves sharing and developing new knowledge outside the firm's own domain (Lavie and Rosenkopf, 2006). It is experimentation with new alternatives; in March's terms, it is "search, variation, risk taking, experimentation, play, flexibility, discovery, innovation". Although firms cannot rely on direct experience when collaborating with a new partner, searching for partners beyond a firm's immediate network offers new opportunities, but uncertainty and risks are definitively higher (Lavie \& Rosenkopf, 2006).

Although Lavie and Rosenkopf (2006) state that a balance between the explorative and the exploitative approaches can be achieved, Holmes and Smart (2009) found that firms with a broad or an undefined engagement scope adopted an explorative approach to search for new innovation opportunities. Firms with a narrow engagement scope and with a predefined remit adopted the exploitative approach, using the skills and resources of their partners.

\section{Innovation and startups}

Startups are often pictured as freshly founded companies with creative youngsters in a garage developing mobile phone apps or high-tech gadgets. However, Ries (2011) notes that the size of the company and its industry sector do not belong to the definition of a startup: instead, innovation is at the heart of every startup. Thus, a refined definition of a startup is "a temporary organisation in search of a scalable, repeatable, profitable business model" (Blank \& Bob, 2012).

Established firms - from small to large - operate in mature markets with known business models (Blank \& Bob, 2012). They offer a product that is successful in the market and focus on optimization and efficient execution of operations. Startups instead are still seeking a 


\title{
Innovation by Collaboration between Startups and SMEs in Switzerland
}

\author{
Fabio Mercandetti, Christine Larbig, Vincenzo Tuozzo, and Thomas Steiner
}

business model and operate in a search mode, turning unknowns into knowns. Prior to market entry, startups are unaware of whether or not their ideas will work. It is about trial and error in situations of extreme uncertainty, seeking a feasible value proposition and a repeatable and scalable business model (Brikman, 2016). Complex processes, demanding influential customers, or the liability of fixed capital and human costs are foreign to startups. Due to startups' proximity to sources of technological knowledge, they are capable of experimenting with different approaches, enabling them to respond with agility to shifting needs (World Economic Forum, 2015). Hence, startups reach the market and produce profits considerably quicker than the innovation initiatives of established firms (Mocker et al., 2015).

\section{Large firms collaborating with startups}

A significant amount of the open innovation literature addresses technology-intensive firms and large corporations. They are aware of the concept of open innovation and consequently collaborate with other partners. Industry leaders such as Apple, BMW, Google, Netflix, and Procter \& Gamble include innovation in their business strategies and embed innovation within their organizations. They proved that innovation is essential for organizations striving to maintain and develop a valuable competitive advantage (Ebert, et al., 2008). In this respect, John Chambers, former President of Cisco Systems stated, "open innovation offers the best platform for leveraging organisational science, knowledge, and experiential learning to foster rapid creative development, implementation, and new business leadership" (Creamer \& Amaria, 2012).

Large firms offer startups business experience and economies of scale, open their working networks to them including loyal customers and established suppliers under the umbrella of a recognized image. Hence, startups can test their products for market fit in that environment and acquire additional expertise about the market and customer needs. This collaboration between "large firms and startups" is a special kind of open innovation, which according to research, has a positive effect on the performance of both startups and established firms (Mocker et al., 2015).

The innovation opportunity for SMEs collaborating with startups

Literature about open innovation addressing collaboration between startups and SMEs is scarce. Nevertheless, SMEs contribute considerably to employment opportunities in all countries, irrespective of the countries' income levels or location. According to the International
Labour Office (2015), a sample of 18 countries by the Organisation for Economic Co-operation and Development (OECD) revealed that SMEs account for $63 \%$ of total employment. Indeed, in the Swiss economy, SMEs employ $68 \%$ of all employees (Swiss Confederation, 2014).

It becomes evident that, nowadays, no company can conduct all R\&D activities in-house (Vanhaverbeke et al., 2012). For SMEs, the innovation process is impaired by limited financial means and competencies, by limited opportunities in recruiting specialists, by insufficient understanding of the newest technologies, and simply by the lack of time. Thus, SMEs need to collaborate with partners in order to remain innovative (Vanhaverbeke et al., 2012). Large companies demonstrate that collaborations with startups enable them to deepen their knowledge and to quickly grasp new opportunities. Therefore, collaboration with startups and young entrepreneurs can likewise contribute to strategic renewal and successful innovation at SMEs (Ketchen et al., 2007).

\section{Research Method}

In a first step, a quantitative approach was undertaken to measure the nature of open innovation initiatives among startups collaborating with SMEs. In total, 138 startup companies were sent a questionnaire to collect both qualitative and quantitative information, such as the timing of collaborations, successes and failures, as well as the rationale for each collaboration. Geographically, 111 companies were in the German-speaking part of Switzerland, whereas 27 in the French-speaking part, approximately reflecting the size of the respective regions. In total, 28 startups answered, which corresponds to $20 \%$ of the sample. This approach allowed objective reporting of reality, showing results with simple descriptive statistics (Davies, 2007). Qualitative information from the survey was useful to better understand the data provided and as a description of the resulting charts. It also led to the identification and selection of startups for a subsequent series of interviews, some of which are presented here as case studies.

In a second step, 20 interviews were conducted. The qualitative research method allowed the reconstruction of events by requiring the interviewee to give reasons, experiences, and explanations (Rubin \& Rubin, 2005). The sample was divided into two subsample groups. The first subsample consisted of 15 startups working in the financial, food, furniture, graphics, microbiology, software, textile, and tourism sectors. For the second 


\section{Innovation by Collaboration between Startups and SMEs in Switzerland}

Fabio Mercandetti, Christine Larbig, Vincenzo Tuozzo, and Thomas Steiner

subsample, five SMEs working in the beverage, fashion, furniture, marketing, and software sectors were interviewed.

The adopted method of research for the interviews was semi-structured, allowing more space for the interviewees to answer on their own terms. However, the main questions were the same for both respective interview groups. Thus, the obtained answers from startups and SMEs allowed a comparison within and between both subsamples. For instance, startups and SMEs were asked about their cooperation efforts, their preferences in selecting a partner (for startups if it was preferably a large company or an SME), how they reached an appropriate partner, how they would rate their experience, and what were the results.

The analysis consisted of preparing the transcripts and coding the interviews by matching what the interviewees said with the relevant themes and concepts. Subsequently, a comparison of the themes and categories across the interviews was made to answer the research question in a way that allows the drawing of broader theoretical conclusions (Rubin \& Rubin, 2005).

\section{Findings: Openness of Startups towards Col- laboration}

Among the survey respondents, $60 \%$ were already cooperating with another company and another $20 \%$ intended to do so soon. This finding reveals how important collaboration is for startups.

Initiation of collaboration:

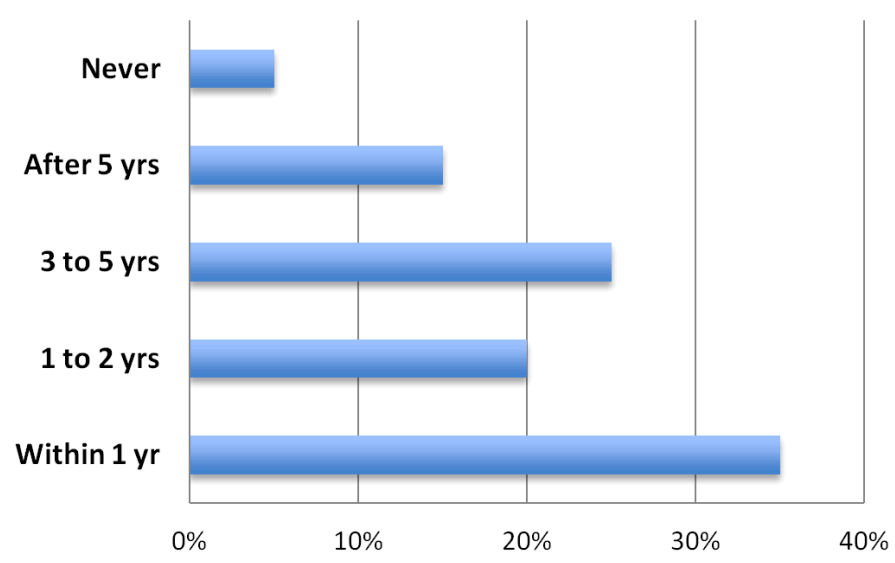

Figure 1. Survey results: when startups first started collaborating with other companies
Many startups entered co-operation agreements at a rather early stage of their company lifecycle: $55 \%$ did so within the first two years (Figure 1). Startups realized that being alone in the business arena is challenging for a newcomer with limited resources and experience. The reasons mentioned in favour of collaboration were: expected support in infrastructure, product development, production, or distribution $(21 \%)$; a better image in the market (18\%); know-how transfer on how to run a business $(18 \%)$; and cost reduction opportunities (14\%). The reasons mentioned against collaboration were: fear of losing freedom (36\%); difficult co-operation and communication (29\%); lack of trust (14\%); and fear of potential conflicts (14\%).

Finding an adequate partner was not always easy for the startups. Among those who found a partner, there was variation in their experiences, as depicted in Figure 2. However, finding an adequate partner did not usually occur through systematic searches. Most frequently, the partner was found within the startup's own network (73\%), followed by business fairs (13\%), advertisements in business papers (7\%), and systematic search projects (7\%). Unfortunately, startups and young entrepreneurs do not commonly possess strong networks.

The "top league" companies of the respective industry sector were targeted as partners in $85 \%$ of the cases. Nevertheless, startups were even open to collaboration with other startups in their quest for synergies. Working with a similarly minded company may accelerate the innovation efforts, thanks to high motivation, entrepreneurial

\section{Finding a partner was:}

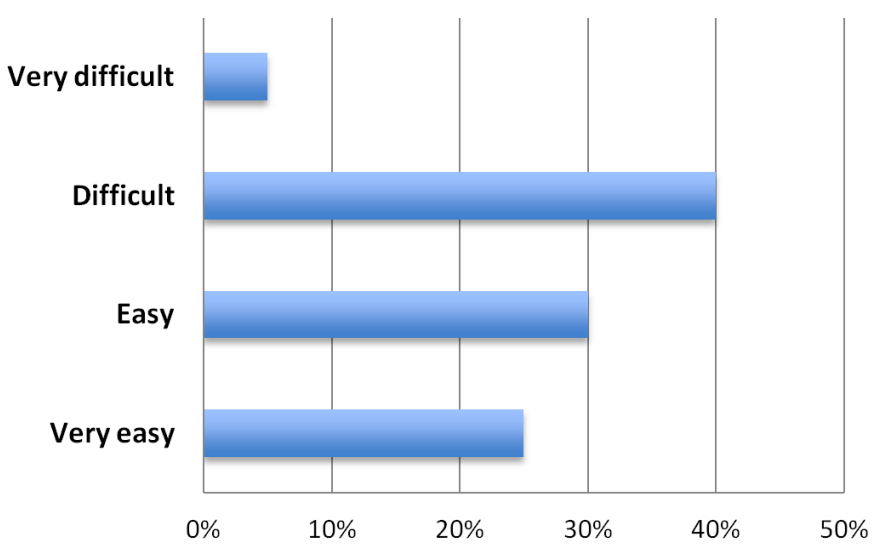

Figure 2. Survey results: how difficult it was for startups to find a partner company to collaborate with 


\title{
Innovation by Collaboration between Startups and SMEs in Switzerland
}

\author{
Fabio Mercandetti, Christine Larbig, Vincenzo Tuozzo, and Thomas Steiner
}

climate, and speed. However, startups did not immediately seek partners among SMEs. First, startups were not aware of them and second, startups feared that a small partner might not be stable enough over time.

Once they did find a partner, the majority of the startups surveyed reported positive experiences (see Figure 3) and could mention more than one positive aspect.

\section{Findings: Collaborations between Startups and SMEs}

When asked to provide a definition of the term "startup", the SME interviewees provided different understandings and associations, indicating different views of what a startup really is. Also, startups perceived resistance to collaboration from SMEs. In addition, SMEs emphasized the efforts required to collaborate, mentioning the fear of losing time and money as reasons for their reduced openness to risk. They mentioned their top target was the prevention of any negative impact on their business performance. Startups appeared venturesome in the area of collaboration, which is not in accordance with the security-focused mentality of the SMEs. Conversely, as demonstrated in the following successful cases of collaboration between startups and SMEs (Cases 1, 2, and 3), there were similarities in the rationale for seeking adequate innovation partners who are willing to collaborate in a successful and fruitful manner.

\section{Collaboration experiences:}

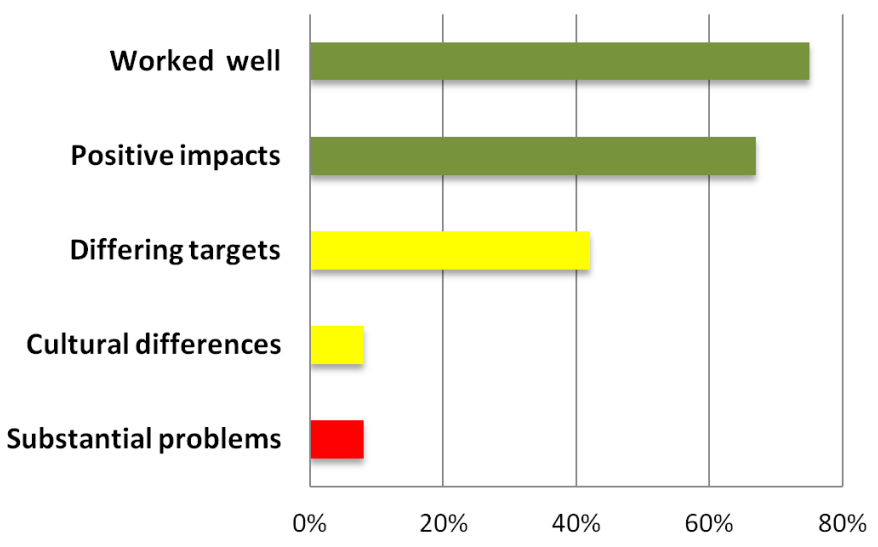

Figure 3. Survey results: how startups perceived the benefits and challenges of collaborating with another company

\section{Rationale for collaboration}

For both SMEs and startups, customer needs constituted the starting point. Finding a solution, solving problems quicker, achieving improved results, and meeting the customers' requests in time were at the forefront. The interviewees had a clear idea of how to meet such requests and were aware of their core capabilities, the complementary resources, and their missing knowledge. Thus, collaborations were considered as a good solution to satisfy such customers' requests and obtain synergies - such as know-how exchange and cost savings. Yet, although SMEs looked to collaborate only when a specific customer request pushed them beyond their own competence area, startups mentioned that collaborations constitute an integral part of their strategy. Consequently, startups more frequently sought partners without a specific customer request and early in their company life. The result was that cooperation agreements between startups and larger companies were more likely to happen than between startups and SMEs.

\section{Finding a partner}

In accordance with the findings above, both startups and SMEs initially used the recommendations from their existing network to find partners to collaborate with, followed by fairs and events - only rarely did they launch an organized search. This was due to lack of time and resources, but also arose from a conservative approach and desire to minimize risks. The key difference

Case 1. Rationale for collaboration

A successful spinoff of a university research project invented a bacterial detection process, useful in the biology and food industry, that was considerably quicker than previous ones. As a newcomer in business, it looked for partners within its own thankfully wide network of research institutes and related players. Specifically, it was seeking knowhow and cost-reduction opportunities.

Hence, from the beginning, it initiated several agreements in different areas, such as with SMEs specialized in equipment, transportation of hazardous materials, and microbiology research. The owner did this systematically and tactically, approaching each collaboration like a project. At given milestones, he checked progress and, if a collaboration was not bringing results, it was attentively scrutinized and then possibly stopped. 


\title{
Innovation by Collaboration between Startups and SMEs in Switzerland
}

\author{
Fabio Mercandetti, Christine Larbig, Vincenzo Tuozzo, and Thomas Steiner
}

between the network of startups and the network of SMEs was structural. Although SMEs relied on longstanding business relationships, startups searched within their circle of friends and acquaintances. Indeed, if a large company might withstand failures, for startups or SMEs with little available resources, selecting the wrong partner could have dramatic consequences. This is why they stayed on familiar ground. However, opportunities for innovation were probably missed by only using their own networks, unless luck played a part.

\section{Respective expectations about a successful collaboration}

An essential aspect mentioned by all interviewees was the concept of give and take. Reciprocity and creating a win-win situation had significant importance. Openness, transparency, and flexibility were additional aspects expected by startups and SMEs in building long-term collaborations. Along with these aspects, business-related expectations were also relevant: firms expected to enlarge their customer base, improve profits, and increase their brand awareness when entering into collaborations. Startups considered team spirit and fairness to be key values in initiating collaborations.

\section{Case 2. Finding a partner}

Following completion of their Bachelor degrees, two recent graduates founded a startup with the aim to design and sell a high-performance, highquality tool for the outdoor sports market. A business incubator gave them office space, where they started with conceptual and detailed design engineering, based on their computer-aided design (CAD) experience and on rapid prototyping using 3D printers. They initiated their first collaboration with an SME that performed mechanical work and assembly for third parties, and this SME was located in their same building. Thus, the partnership was not the result of a search, it was just luck and compatibility. This partner started producing parts for the startup while they produced technical drawings for the SME, resulting in more business for both. They found a second partner, a producer of industrial 3D plastic parts, at a business fair. This collaboration increased the number of orders as well as the exchange of know-how.

Both collaborations took place at the very beginning of the startup's lifecycle; were set for the long-term; were built on trust, seeking synergy, and the transfer of know-how; and were successful.
Decisions were almost always made based on soft factors such as perceived compatibility, a reliance on personal intuition, and a perception of "the right chemistry" between partners.

It is important to emphasize that, although SMEs demonstrated a willingness to open up to external innovation, their internal time-consuming procedures and the differences in expectations often impeded successful collaborations with startups. Hierarchical structures and the difficulty of finding people responsible for taking decisions were inadequate when working with fast-moving entrepreneurs. One startup mentioned a case where 17 signatures were required within a firm in order to obtain approval, which unduly delayed the process. Also, the expectations were transmitted with insufficient clarity and transparency to the person responsible within the SME organization. Moreover, an absence of structure in the SMEs was stressed as an issue by startups and by SMEs. The interviewees referred to this as an impediment to initiating collaborations in the right place at the right time.

In contrast to the approach taken by large companies, where collaborations with startups are sought to exploit innovative ideas outside their own core competencies, both startups and SMEs stated a customer need to be the initial motive for seeking partners. Startups and SMEs can combine their know-how, core capabilities, and complementary resources. Because both possess

Case 3. Respective expectations about a successful collaboration

A startup developed a process to produce fruit drinks that would retain the high quality of the fruits, which resulted in a much tastier drink. It partnered from the beginning with a completely unrelated SME - a well-known manufacturer of household appliances. This relationship offered immediate visibility in the market with a very limited marketing investment. Growth followed, and it was a win-win situation for both companies.

A negative experience came from another producer of drinks that was interested in a portfolio expansion: the proposed contract was too complicated and conditions were unfavourable. For this reason, the startup owner decided not to sign collaboration contracts anymore and would base any further collaboration purely on trust. 


\title{
Innovation by Collaboration between Startups and SMEs in Switzerland
}

\author{
Fabio Mercandetti, Christine Larbig, Vincenzo Tuozzo, and Thomas Steiner
}

customer proximity and great flexibility in meeting specific customer's needs, they may have an advantageous competitive position in the market. Hence, it is important to create joint opportunities where startups can scale their business model and SMEs can simultaneously ensure their goal of growing and remaining a valuable market player.

Furthermore, trust, reciprocity, loyalty, and commitment are the crucial conditions to achieve successful collaborations for both startups and SMEs: personal intuition is, by and large, decisive when selecting a partner to collaborate with.

The approach of startups is more tactical than strategic. The preferred partner is the company that seems to better suit the customer's needs and is more inclined to help. This is more often a larger company than an SME, because these appear to be generally less attentive to the innovation potential offered by startups.

Thus, the process of searching for the right partners is still currently sub-optimal. Many more collaborations could be initiated if only the SMEs knew of the existence of appropriate startups and vice versa.

\section{Conclusion}

In conclusion, based on our analyses, we propose the following actions. All companies, including SMEs, must keep their technology portfolio up-to-date to sustain their business success in the long run. Particularly because of the "Internet of Things" revolution, companies will have to watch and evaluate technologies that they never considered before, or have very little knowledge of. In addition, they will have to implement new technologies faster than in the past - and continuously.

Monitoring technological trends, however, requires time, expert resources and money. Some companies even pay for external parties and technology monitoring tools. It is obvious that such practices are a big effort, often too big for SMEs, considering their limited human and financial resources. The quantity of information to analyse will be vast, but in spite of the help of the Internet, reaching the "right" information will be a challenge.

On the other hand, startups develop their offerings in new technological domains but have little idea of the application fields or of the industry sectors where their innovations could add value and close the innovation gap. They often do not know which markets and collaboration opportunities they should pursue, and move only within their own network. Sometimes, lists of players and technologies offered are prepared, and universities or industry associations organize meetings between established firms and startups. However, participants are few, and they seldom obtain enough information for effective matchmaking.

Therefore, considering the difficulty that both SMEs and startups encounter in first becoming aware of each other, then meeting, and eventually initiating collaboration, two schools at the Lucerne University of Applied Sciences and Arts in Switzerland - the Institute for Innovation and Technology (tinyurl.com/yaynnzp3) and the Lucerne School of Information Technology (tinyurl.com/ y8wf4327) - are about to launch a project with the aim to build bridges between SMEs and startups (Hohmann, 2016). The objective is enabling collaborative innovation based on a shared platform that will support an active matching of interested SMEs and startups. Both will submit standardized documents covering their technology profiles, patents, product portfolios, and expectations, which will facilitate the matchmaking process. The input and the maintenance of such documentation over time is designed to be simple and cost-effective. Particular attention will be given to the protection of confidential information. An IT developer will provide artificial intelligence software that will scan all submitted documents to find common ground upon which to propose meaningful matches to members of the platform and initiate discussions about potential collaborations.

This or similar initiatives may be helpful in bringing down the walls between startups and SMEs and foster innovation by cooperation. But we strongly invite the top managers of SMEs to move out of their "comfort zones": we argue that traditional ways of thinking will not help their companies to solve their innovation problems as effectively as intelligent cooperation with startups.

\section{Limitations and future research}

Although our research has revealed important insights on the perception of collaborations among startups and SMEs, it has some limitations. First, the response rate to the survey was reasonable but not as high as expected, and the number of interviews conducted was limited. Both of these factors limit the extent to which the findings can be generalized. However, these limitations must be considered in light of the overall purpose of the study, which was to raise interest in the topic and give some guidance on where further research and actions could be based. 


\title{
Innovation by Collaboration between Startups and SMEs in Switzerland
}

\author{
Fabio Mercandetti, Christine Larbig, Vincenzo Tuozzo, and Thomas Steiner
}

Attention should definitely be devoted to the SME arena, to shed light on how open innovation initiatives can be stimulated in successful, knowledgeable companies with limited resources and risk-averse attitudes. Moreover, it could be of interest to compare the findings of this study (focused only on the Swiss landscape) with the situation in other countries in the European Union. Finally, we encourage local authorities and organizations to organize workshops and events for SMEs where they can meet startups and eventually initiate collaborations. Such networking may be nothing new, but it is still an area that needs attention given the difficulties startups and SMEs have in simply becoming aware of each other and learning more about their potentially complementary needs and competences.

\section{About the Authors}

Fabio Mercandetti is a Professor at the Lucerne School of Engineering and Architecture in Switzerland. He holds an MSc in Chemical Engineering from the Technical University (Politecnico) of Turin, Italy, he has held different management positions up to the Executive Committee in global companies, where he led the Operations and/or the Corporate development function. He teaches in Engineering Bachelor and Masters programmes. His applied research focuses on both operational excellence and lean manufacturing, to help companies, particularly SMEs, to improve and increase their business. This includes finding and rightly approaching co-operation opportunities.

Christine Larbig is a Professor at the Lucerne University of Applied Sciences and Arts Information Technology in Switzerland. She earned her doctoral degree in Management from Cass Business School City University in London, England, and she earned her Master's in Management from Ashridge Management College in Berkhamsted, England. At the Lucerne University of Applied Sciences and Arts, she teaches operations management and researches in the realm of service and social innovation as well as social informatics.

\section{Acknowledgements}

This article was developed from a paper presented at the ISPIM Innovation Conference in Vienna, Austria, June 18-21, 2017. ISPIM (ispim-innovation.com) - the International Society for Professional Innovation Management - is a network of researchers, industrialists, consultants, and public bodies who share an interest in innovation management.

Vincenzo Tuozzo is graduate of the Lucerne University of Applied Sciences and Arts (HSLU) in Switzerland, where he obtained a BA degree in International Management and Economics. He has been active in the area of innovation management and collaboration. With the support of Fabio Mercandetti, Professor of Operations Management at HSLU, and Prof. Dr. Christine Larbig, Professor of Social Innovation at HSLU, he has been researching the theory of open innovation and its practice between startups and SMEs in Switzerland. The focus of their current research lies in recognizing cooperation opportunities and prescribing measures on how to promote such collaborations with the aim of enhancing the innovation processes of startups and SMEs.

Thomas Steiner is a business product developer who, in 2016, completed his Bachelor`s degree studies in Business Engineering Innovation at the Lucerne University of Applied Sciences and Arts (HSLU) in Switzerland. Within an industrial project at the HSLU, supported by Fabio Mercandetti, Professor of Operations Management at the HSLU, he researched the possibilities and needs for collaboration between startups and SMEs in Switzerland. His current professional activities at an SME focus on issues such as innovation management, lean product development, and business modelling. 


\title{
Innovation by Collaboration between Startups and SMEs in Switzerland
}

\author{
Fabio Mercandetti, Christine Larbig, Vincenzo Tuozzo, and Thomas Steiner
}

\section{References}

Blank, S., \& Bob, D. 2012. The Startup Owner's Manual. Pescadero, CA: K\&S Ranch, Inc.

Brikman, Y. 2016. Hello, Startup: A Programmer's Guide to Building Products, Technologies, and Teams. North Sebastopol, CA: O’Reilly Media, Inc.

Chesbrough, H., \& Crowther, A. K. 2006. Beyond High Tech: Early Adopters of Open Innovation in Other Industries. $R \& D$ Management, 36(3): 229-236.

http://doi.org/10.1111/j.1467-9310.2006.00428.x

Creamer, W. P., \& Amaria, P. 2012. The Effect of Business Transformation and Innovation Economics on Sustainable Corporate Competitive Advantage. Research in Business and Economics Journal, 6: 1-34.

Davies, M. B. 2007. Doing a Successful Research Project: Using Qualitative or Quantitative Methods. New York, NY: Palgrave Macmillan.

Ebert, J., Chandra, S., \& Liedtke, A. 2008. Innovation Management, Strategies for Success and Leadership. Chicago, IL: At Kearney.

Hohmann, C. 2016. Projektskizze: Technologieorientiertes Matching von KMUs und Start-Ups. Lucerne, Switzerland: Lucerne University of Applied Sciences and Arts.

Holmes, S., \& Smart, P. 2009. Exploring Open Innovation Practice in Firm-Nonprofit Engagements: A Corporate Social Responsibility Perspective. R\&D Management, 39(4): 394-409.

http://doi.org/10.1111/j.1467-9310.2009.00569.x

Ketchen, D. J., Jr., Ireland, R. D., \& Snow, C. C. 2007. Strategic Entrepreneurship, Collaborative Innovation, and Wealth Creation. Strategic Entrepreneurship Journal, 1(3-4): 371-385. http://doi.org/10.1002/sej.20

Lavie, D., \& Rosenkopf, L. 2006. Balancing Exploration and Exploitation in Alliance Formation. Academy of Management Journal, 49(4): 797-818. http://doi.org/10.5465/AMJ.2006.22083085

Levinthal, D. A., \& March, J. G. 1993. The Myopia of Learning. Strategic Management Journal, 14(52): 95-112. http://doi.org/10.1002/smj.4250141009

Lichtenthaler, U. 2011. Open Innovation: Past Research, Current Debates, and Future Directions. Academy of Management Perspectives, 25(1): 75-93.
March, J. G. 1991. Exploration and Exploitation in Organizational Learning. Organization Science, 2(1): 71-87. https://doi.org/10.1287/orsc.2.1.71

Mocker, V., Bielli, S., \& Haley, C. 2015. Winning Together: A Guide to Successful Corporate-Startup Collaborations. London: Startup Europe Partnership.

OECD. 2005. Handbook on Economic Globalisation Indicators. Paris: OECD Publishing.

Pénin, J., Hussler, C., \& Burger-Helmchen, T. 2011. New Shapes and New Stakes, a Portrait of Open Innovation as a Promising Phenomenon. Journal of Innovation Economics \& Management, 7(1): 11-29. http://doi.org/10.3917/jie.007.0011

Ries, E. 2011. The Lean Startup. New York: Random House, Inc.

Rubin, H. J., \& Rubin, I. S. 2005. Qualitative Interviewing: The Art of Hearing Data. London: Sage.

Steiner, T. 2015. Kooperationen bei Startup-Firmen: Was und Wie? Industry Project. Lucerne, Switzerland: Lucerne University of Applied Sciences and Arts.

Swiss Confederation. 2014. KMU in Zahlen: Firmen und Beschäftigte. Swiss Confederation. Accessed April 24, 2017: https://www.kmu.admin.ch/kmu/de/home/kmu-politik/kmupolitik-zahlen-und-fakten/kmu-in-zahlen/firmen-undbeschaeftigte.html

Tuozzo, V. 2016. Open Innovation: Collaborations of Startup Firms. Bachelor Thesis. Lucerne University of Applied Sciences and Arts.

van der Vrande, V., de Jong, J. P. J., Vanhaverbeke, W., \& de Rochemont, M. 2009. Open Innovation in SMEs: Trends, Motives and Management Challenges. Technovation, 29(6): 423-437. https://doi.org/10.1016/j.technovation.2008.10.001

Vanhaverbeke, W., Vermeersch, I., \& de Zutter, S. 2012. Open Innovation in SMEs: How Can Small Companies and Start-Ups Benefit from Open Innovation Strategies? Leuven, Belgium: Flanders DC.

Vanhaverbeke, W., \& Roijakkerspp, N. 2013. Enriching Open Innovation Theory and Practice by Strengthening the Relationship with Strategic Thinking. Berlin: Springer Verlag.

World Economic Forum. 2015. Collaborative Innovation Transforming Business, Driving Growth. Geneva: World Economic Forum. 


\section{Academic Affiliations and Funding Acknowledgements}

Canadà
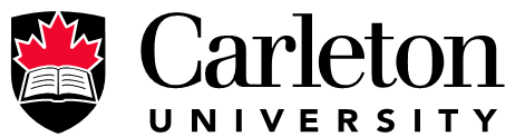

U N I V E R S I T Y

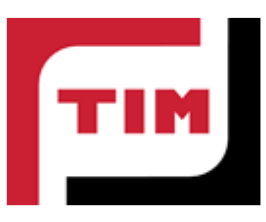

The Federal Economic Development Agency for Southern Ontario (FedDev Ontario; feddevontario.gc.ca) is part of the Innovation, Science and Economic Development portfolio and one of six regional development agencies, each of which helps to address key economic challenges by providing regionallytailored programs, services, knowledge and expertise.

- The TIM Review receives partial funding from FedDev Ontario's Investing in Regional Diversification initiative.

Technology Innovation Management (TIM; timprogram.ca) is an international master's level program at Carleton University in Ottawa, Canada. It leads to a Master of Applied Science (M.A.Sc.) degree, a Master of Engineering (M.Eng.) degree, or a Master of Entrepreneurship (M.Ent.) degree. The objective of this program is to train aspiring entrepreneurs on creating wealth at the early stages of company or opportunity lifecycles.

- The TIM Review is published in association with and receives partial funding from the TIM program. 